\title{
Association of nuclear FOXP3 expression with low Ki67 index and better prognosis in patients with breast invasive ductal carcinoma
}

\author{
J. LI' ${ }^{1}$ X. ZHANG ${ }^{2}$, L. ZHENG ${ }^{3}$, Y. LIU', \\ ${ }^{1}$ Department of breast surgery, the Fourth Hospital of Hebei Medical University, Hebei Shijiazhuang 050011, China; ${ }^{2}$ Research Center, the Fourth \\ Hospital of Hebei Medical University, Hebei Shijiazhuang 050011, China; ${ }^{3}$ Department of vascular surgery, the First Hospital of Hebei Medical \\ University, Hebei Shijiazhuang 050011, China.
}

${ }^{*}$ Correspondence: lyj818326@126.com

Received October 15, 2016 / Accepted February 14, 2017

\begin{abstract}
Recent studies have provided clear evidence that some types of human cancer cells expressed Forkhead Box Protein 3 (FOXP3). However, the presence and role of FOXP3 in breast cancer are still contradictory up to now. In this study, we detected the expression of FOXP3 protein by immunohistochemistry in 123 cases of breast invasive ductal carcinoma. It exhibited that the subcellular localization of FOXP3 expression in breast cancer cells is heterogeneous. In nucleus, FOXP3 expression ratio was $47.97 \%$ (59/123) and the nuclear FOXP3 expression was significantly associated with lower Ki67 index $(\mathrm{P}=0.041)$, negative vessel tumor embolus $(\mathrm{P}=0.024)$. It was also significantly correlated with the molecular subtypes of breast cancer $(\mathrm{P}=0.002)$, displaying the highest ratio in the Luminal A subtype $(68.18 \%)$. Kaplan-Meier analysis indicated that high nuclear FOXP3 expression was associated with better overall survival (OS) (94.92\% vs. 82.81\%, $\mathrm{P}=0.022)$ and disease-free survival (DFS) $(91.53 \%$ vs. $76.56 \%, \mathrm{P}=0.026)$. Moreover, nuclear FOXP3 represented an independent prognostic factor for OS $(\mathrm{P}=0.033)$ in multivariate analysis. However, in cytoplasm, FOXP3 expression ratio was $63.41 \%(78 / 123)$ and no statistic prognostic significance was found. Thus, our data demonstrated that nuclear FOXP3 expression correlated with low Ki-67 index and better outcome in breast invasive ductal carcinoma, indicating that FOXP3 acted as a potential prognostic marker for breast cancer.
\end{abstract}

Key words: breast cancer, FOXP3, Ki67, prognosis

Forkhead Box Protein 3 (FOXP3), which located on the short arm of the X chromosome at Xp.11.23, is a key transcription factor and a well-known hallmark of immunosuppressive $\mathrm{CD} 4{ }^{+} \mathrm{CD} 25^{+}$regulatory T cells (Treg) [1]. FOXP3 plays a crucial role in the generation of Treg, which is critical for immune homeostasis maintaining. Loss of FOXP3 function leads to the lack of Treg, resulting in lethal autoaggressive lymphoproliferation and immune tolerance deficency, whereas overexpression of FOXP3 results in severe immunodeficiency [2].

During the past decades, the definition that FOXP3 expression was restricted to Treg has been gradually revised. Recent studies have provided clear evidence that some types of human carcinoma cells also expressed FOXP3, which may play an important role in tumor pathogenesis and development. Some data point to the association between tumor FOXP3 expression and poor prognosis of patients with different cancers, including the bladder cancer, pancreatic cancer, melanoma, and gastric cancer $[1,2]$. However, there is still no consensus on the presence and function of FOXP3 in human breast cancer cells up to now. As a transcription factor in lymphoid cells, FOXP3 should be mainly expressed in the nucleus [3]. In fact, the subcellular localization of FOXP3 in breast cancer cells is heterogeneous, including the nucleus and the cytoplasm [4]. And prognostic implication of FOXP3 expression in breast cancer cells is still a matter of debate. Preclinical researches have reported that FOXP3, as a tumor suppressor gene, participates in breast cancer development by repressing the expression of some oncogenes involved in mammary carcinogenesis in transcriptional level, such as human epidermal growth factor receptor (HER)-2 and S-phase kinase-associated protein (SKP)-2 [3, 5, 6]. However, the clinical studies of human cancer samples revealed a conflicting correlation of FOXP3 expression with prognosis [4, 7-9]. Ladoire S et al. [8] suggested that cytoplasmic and/ 
or nuclear FOXP3 expression was associated with better OS in HER2+ breast cancer patients treated with neo-adjuvant chemotherapy. In contrast, Kim et al. [9] found that cytoplasmic and/or nuclear FOXP3 expression was related to poor DFS and disease-specific survival (DSS) in the node-positive breast cancer patients. An agreement on the prognostic value of FOXP3 in breast cancer has not be reached.

Thus, we designed this study to evaluate the FOXP3 protein expression in breast invasive ductal carcinoma in a cohort of 123 patients, aiming to explore the association between FOXP3 expression and the prognosis of patients with breast cancer.

\section{Patients and methods}

Patients and tissues. The present study included 123 females who underwent primary surgery at Department of Breast Surgery in the Fourth Hospital of Hebei Medical University from January 2009 to April 2012, without any neoadjuvant therapy, including radiation therapy, systemic chemotherapy or hormone therapy. All patients were followed up after surgery until the date of death or July 2016. Formalinfixed, paraffin-embedded specimens from 123 patients were retrieved and reassessed by examining hematoxylin and eosin-stained histologic sections. The histologic type of all the specimens was reconfirmed as breast invasive ductal carcinoma, according to the WHO classification. Histologic grading was carried out using the Nottingham-combined histologic grade (Elston-Ellis modification of Scarff-Bloom-Richardson (SBR) grading system) [10]. The pathologic TNM stage was judged according to the $7^{\text {th }}$ American Joint Committee on Cancer (AJCC). The Ki67 index was scored as high when 30\% or more of the tumor cells were expressed [11]. Analyses for estrogen receptor (ER), progesterone receptor (PR) and HER2 were conducted according to the recommended guidelines of the American Society of Clinical Oncology and College of American Pathologists $[12,13]$. The specimens with an HER2 IHC score of $2+$ were removed in our study. The molecular subtype was classified according to 14th St. Gallen International Expert Consensus. Appropriate adjuvant treatments after the surgery were conducted according to the standard guidelines. Most of the hormone receptor positive patients received the adjuvant hormone therapy for at least 5 years. None of the patients received the HER2-targeted adjuvant therapy. The baseline characteristics of the 123 patients in this study are indicated in Table 1. The study was approved by the institutional ethnics committee of the Fourth Hospital of Hebei Medical University.

Immunohistochemical staining and evaluation of FOXP3. FOXP3 expression was analyzed immunohistochemically on Formalin-fixed, paraffin-embedded tumor sections using mouse antihuman FOXP3 monoclonal antibody (clone ab20034, 1:50 dilution; Abcam, Cambridge, UK). The appropriate antibody concentration was determined via serial dilution for each immunohisto- chemical assay with an identically embedded breast cancer tissue block. Intrinsic peroxidase activity was blocked by peroxidase-blocking reagent for $10 \mathrm{~min}$. Antigen retrieval was carried out by heating slides for 15 minutes at $95^{\circ} \mathrm{C}$ in citrate buffer (pH6.0). A blocking reagent was added for 10 minutes after quenching the endogenous peroxidase activity in $0.3 \%$ hydrogen peroxide for 10 minutes. Specimens were incubated with the FOXP 3 antibody above at $4^{\circ} \mathrm{C}$ overnight. After incubation with primary antibody, immunodetection was performed with biotinylated anti-mouse immunoglobulin for 30 minutes at room temperature, followed by $3,3^{\prime}$-diaminobenzidine chromogenic as a substrate to visualize the slides and Harris hematoxylin for counterstaining. Positive and negative staining controls were carried out with

Table 1.Clinicopathological Characteristics of Patients

\begin{tabular}{|c|c|c|}
\hline Characteristic & No. (123) & $\%$ \\
\hline \multicolumn{3}{|l|}{ Age (years) } \\
\hline$<50$ & 68 & $55.28 \%$ \\
\hline$\geq 50$ & 55 & $44.72 \%$ \\
\hline \multicolumn{3}{|l|}{ Tumor size $(\mathrm{cm})$} \\
\hline$\leq 2.0$ & 66 & $53.66 \%$ \\
\hline$>2.0$ & 57 & $46.34 \%$ \\
\hline \multicolumn{3}{|l|}{ Positive nodes } \\
\hline- & 65 & $52.85 \%$ \\
\hline+ & 58 & $47.15 \%$ \\
\hline \multicolumn{3}{|l|}{ TNM stage } \\
\hline I & 37 & $30.08 \%$ \\
\hline II & 67 & $54.47 \%$ \\
\hline III & 19 & $15.45 \%$ \\
\hline \multicolumn{3}{|l|}{ Histologic Grade } \\
\hline 1 & 26 & $21.14 \%$ \\
\hline 2 & 75 & $60.97 \%$ \\
\hline 3 & 22 & $17.89 \%$ \\
\hline \multicolumn{3}{|c|}{ Vessel tumor embolus } \\
\hline Negative & 86 & $69.92 \%$ \\
\hline Positive & 37 & $30.08 \%$ \\
\hline \multicolumn{3}{|l|}{ Ki67 } \\
\hline Low $(\leq 30 \%)$ & 39 & $26.83 \%$ \\
\hline High (>30\%) & 84 & $73.17 \%$ \\
\hline \multicolumn{3}{|l|}{$\mathrm{ER} / \mathrm{PR}$} \\
\hline Negative & 57 & $46.34 \%$ \\
\hline Positive & 66 & $53.66 \%$ \\
\hline \multicolumn{3}{|l|}{ HER2 } \\
\hline Negative & 78 & $63.41 \%$ \\
\hline Positive & 45 & $36.59 \%$ \\
\hline \multicolumn{3}{|l|}{ Subtype } \\
\hline Luminal A & 22 & $17.88 \%$ \\
\hline Luminal B & 44 & $35.77 \%$ \\
\hline HER2 & 32 & $26.02 \%$ \\
\hline TNBC & 25 & $20.33 \%$ \\
\hline
\end{tabular}

FOXP3, Forkhead Box Protein 3; HER2,human epidermal growth factor receptor 2; TNBC, triple negative breast cancer. 
Table 2. Localization of POXP3 expression

\begin{tabular}{lccc}
\hline \multirow{2}{*}{$\begin{array}{l}\text { Characteristic } \\
(\mathrm{n}=123)\end{array}$} & & \multicolumn{2}{c}{ Nucleus FOXP3 } \\
\cline { 3 - 4 } & & FOXP3+ $(\mathrm{n}=59)$ & FOXP3- $(\mathrm{n}=64)$ \\
\hline Cytoplasm & FOXP3+ $(\mathrm{n}=78)$ & 53 & 25 \\
FOXP3 & FOXP3- $(\mathrm{n}=45)$ & 6 & 39 \\
\hline
\end{tabular}

FOXP3, Forkhead Box Protein 3.

paraffin tonsil sections using the same antibody above and an appropriate isotype-matched negative control antibody (mouse IgG1, ZSGB-BIO, China). Staining of at least 25\% of the cells was considered positive for FOXP3 expression
(FOXP3+) [4]. The staining was interpreted by two of the authors, both blinded to clinicalpathological data. Discrepancies were reviewed jointly and a consensus was reached.

Statistical analysis. All analyses were conducted using SPSS for Windows, version 21.0. The association between the FOXP3 expression and pathologic characteristics was examined using Chi square statistical tests. OS and DFS were calculated from the time of diagnosis to the time of event of interest, death from any cause, recurrence, or the final follow-up date. The Kaplan-Meier method was used for survival analysis and the unstratified log-rank test was adopted for comparison. Cox proportional hazards model was used to estimate the hazard ratio (HR) of each clinicopathologic

Table 3. FOXP3 expression in breast cancer cells according to clinicopathologic parameters

\begin{tabular}{|c|c|c|c|c|c|c|c|c|c|c|}
\hline \multirow{2}{*}{ Characteristic } & \multirow{2}{*}{$\begin{array}{l}\text { No. } \\
(123)\end{array}$} & \multicolumn{2}{|c|}{$\begin{array}{c}\text { Tumor FOXP3 } \\
\text { expression }\end{array}$} & \multirow{2}{*}{$\mathrm{P}$} & \multicolumn{2}{|c|}{$\begin{array}{c}\text { Nuclear FOXP3 } \\
\text { expression }\end{array}$} & \multirow{2}{*}{$\mathrm{P}$} & \multicolumn{2}{|c|}{$\begin{array}{c}\text { Cytoplasmic FOXP3 } \\
\text { expression }\end{array}$} & \multirow{2}{*}{$\mathrm{P}$} \\
\hline & & $\begin{array}{l}\text { negative } \\
(n=39)\end{array}$ & $\begin{array}{l}\text { positive } \\
(\mathrm{n}=84)\end{array}$ & & $\begin{array}{l}\text { negative } \\
(\mathrm{n}=64)\end{array}$ & $\begin{array}{l}\text { positive } \\
(\mathrm{n}=59)\end{array}$ & & $\begin{array}{l}\text { negative } \\
(\mathrm{n}=45)\end{array}$ & $\begin{array}{l}\text { positive } \\
(\mathrm{n}=78)\end{array}$ & \\
\hline \multicolumn{11}{|l|}{ Age, years } \\
\hline$<50$ & 68 & 20 & 48 & 0.543 & 35 & 33 & 0.484 & 24 & 44 & 0.741 \\
\hline$\geq 50$ & 55 & 19 & 36 & & 29 & 26 & & 21 & 34 & \\
\hline \multicolumn{11}{|l|}{ Tumor size, $\mathrm{cm}$} \\
\hline$\leq 2.0$ & 66 & 21 & 45 & 0.956 & 34 & 32 & 0.902 & 21 & 42 & 0.443 \\
\hline$>2.0$ & 57 & 18 & 39 & & 30 & 27 & & 24 & 36 & \\
\hline \multicolumn{11}{|l|}{ Positive nodes } \\
\hline negative & 65 & 17 & 48 & 0.161 & 31 & 34 & 0.308 & 31 & 44 & 0.996 \\
\hline positive & 58 & 22 & 36 & & 33 & 25 & & 24 & 34 & \\
\hline \multicolumn{11}{|l|}{ TNM stage } \\
\hline I & 37 & 7 & 30 & 0.074 & 14 & 23 & 0.106 & 10 & 27 & 0.167 \\
\hline II & 67 & 23 & 44 & & 38 & 29 & & 25 & 42 & \\
\hline III & 19 & 9 & 10 & & 12 & 7 & & 10 & 9 & \\
\hline \multicolumn{11}{|l|}{ Histologic grade } \\
\hline 1 & 26 & 7 & 19 & 0.678 & 13 & 13 & 0.766 & 8 & 18 & 0.381 \\
\hline 2 & 75 & 26 & 49 & & 38 & 37 & & 31 & 44 & \\
\hline 3 & 22 & 6 & 16 & & 13 & 9 & & 6 & 16 & \\
\hline \multicolumn{11}{|c|}{ Vessel tumor embolus } \\
\hline Negative & 86 & 20 & 66 & 0.002 & 39 & 47 & 0.024 & 25 & 61 & 0.008 \\
\hline Positive & 37 & 19 & 18 & & 25 & 12 & & 20 & 17 & \\
\hline \multicolumn{11}{|l|}{ Ki67 } \\
\hline Low $(\leq 30 \%)$ & 39 & 12 & 27 & 0.879 & 15 & 24 & 0.041 & 16 & 23 & 0.486 \\
\hline $\operatorname{High}(>30 \%)$ & 84 & 27 & 57 & & 49 & 35 & & 29 & 55 & \\
\hline \multicolumn{11}{|l|}{$\mathrm{ER} / \mathrm{PR}$} \\
\hline Negative & 57 & 12 & 45 & 0.018 & 25 & 32 & 0.092 & 12 & 45 & 0.001 \\
\hline Positive & 66 & 27 & 39 & & 39 & 27 & & 33 & 33 & \\
\hline \multicolumn{11}{|l|}{ HER2 } \\
\hline Negative & 78 & 27 & 51 & 0.362 & 42 & 36 & 0.596 & 31 & 47 & 0.338 \\
\hline Positive & 45 & 12 & 33 & & 22 & 23 & & 14 & 31 & \\
\hline \multicolumn{11}{|l|}{ Subtype } \\
\hline Luminal A & 22 & 6 & 16 & 0.018 & 7 & 15 & 0.002 & 9 & 13 & 0.003 \\
\hline Luminal B & 44 & 21 & 23 & & 32 & 12 & & 24 & 20 & \\
\hline HER2 & 32 & 9 & 23 & & 13 & 19 & & 9 & 23 & \\
\hline TNBC & 25 & 3 & 22 & & 12 & 13 & & 3 & 22 & \\
\hline
\end{tabular}

FOXP3, Forkhead Box Protein 3; HER2,human epidermal growth factor receptor 2; TNBC, triple negative breast cancer. 


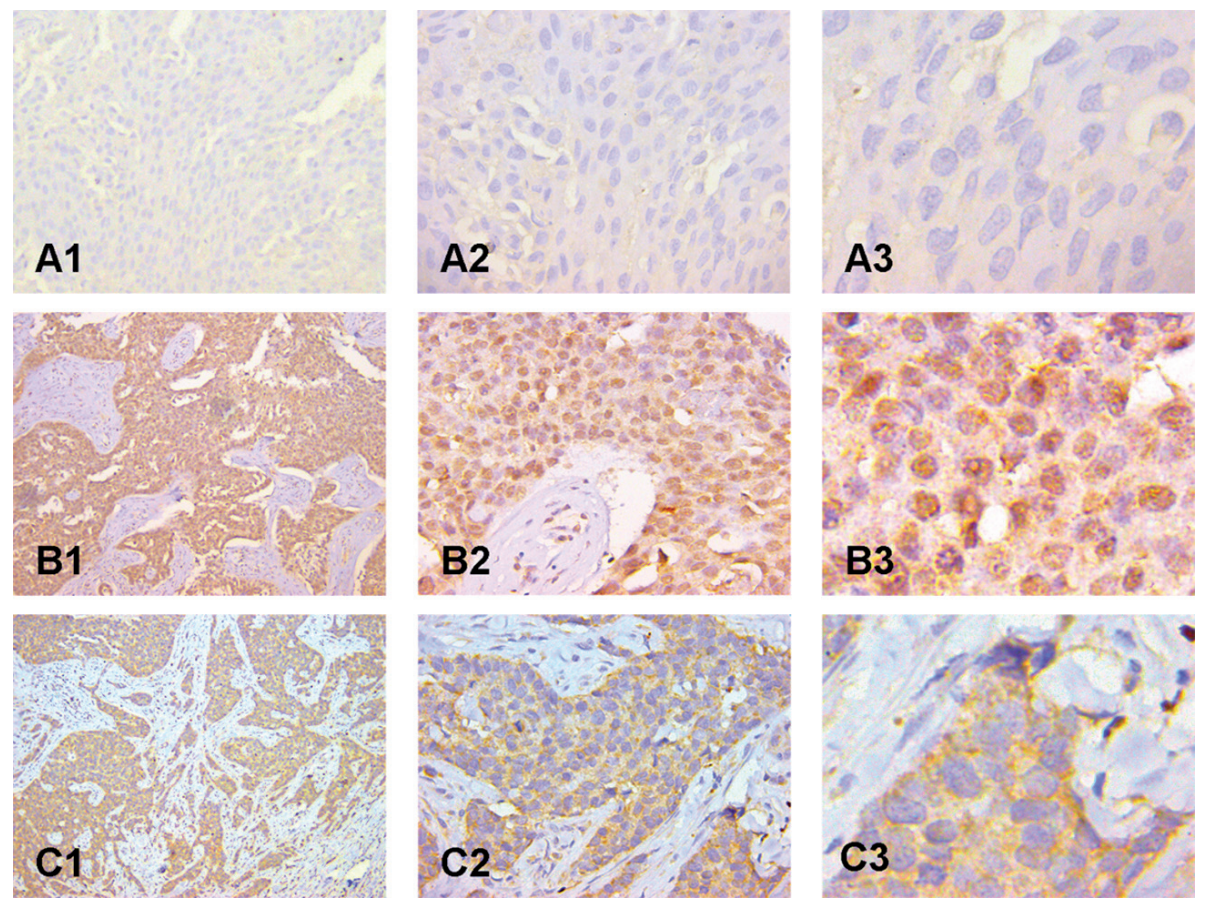

Figure 1. Immunohistochemical forkhead box protein 3 (FOXP3) staining in breast cancer. Representative images of FOXP3 expression in tumor cells: FOXP3 negative (A), nuclear-FOXP3 positive $(B)$ and cytoplasmic FOXP3-positive $(\mathrm{C})($ magnification, $\times 100, \times 200, \times 400$, respectively).

variables for OS and DFS. All predictors with $\mathrm{P}$ value $<0.05$ in univariate Cox analyses were used in multivariate analysis. $\mathrm{P}$ values were two-tailed and $\mathrm{P}<0.05$ was considered statistically significant.

\section{Results}

Patient characteristics. The median age of the 123 female patients was 48 years (range, 27 to 81 ). Half of all the patients presented with stage T1 tumor and $47.15 \%(58 / 123)$ had clinically detectable axillary lymph node metastasis. Around one third of the patients presented with vessel tumor embolus, and 73.17\% (84/123) with high Ki67 index. The median followup of the 123 patients was 67 months (range, 7 to 81 ), with 14 patients died at data cut-off. The 5-years OS and DFS rates were $88.62 \%$ and $83.70 \%$, respectively. Clinicalpathological characteristics of the patients were demonstrated in Table 1.

FOXP3 expression and clinical features. The subcellular localization of FOXP3 in breast cancer cells is heterogeneous, instead of a mainly location of the nucleus in lymphoid cells $[3,4]$. Using the criteria described above, we also found that FOXP3 exhibited a heterogeneous subcellular location in both tumor nucleus and cytoplasm (Figure 1, Table 2, 3 ). The expression ratio of tumor FOXP3 (in nucleus and/ or cytoplasm) was $68.29 \%(84 / 123)$ and it was significantly associated with negative vessel tumor embolus $(\mathrm{P}=0.002)$, negative ER status $(\mathrm{P}=0.018)$ and molecular subtype $(\mathrm{P}=0.018)$ significantly, displaying the highest ratio in the
TNBC $(88.00 \%)$. The expression ratio of nuclear FOXP3 was $47.97 \%(59 / 123)$ and it was significantly associated with lower Ki67 index $(\mathrm{P}=0.041)$, negative vessel tumor embolus $(\mathrm{P}=0.024)$ and molecular subtype $(\mathrm{P}=0.002)$, displaying the highest ratio in the Luminal A breast cancer $(68.18 \%)$. The expression ratio of cytoplasmic FOXP3 was $63.41 \%$ (78/123) and it was significantly associated with negative vessel tumor embolus $(\mathrm{P}=0.017)$, negative ER status $(\mathrm{P}=0.001)$ and molecular subtype $(\mathrm{P}=0.001)$ significantly, displaying the highest ratio in the TNBC (68.18\%).

FOXP3 expression and survival analysis: univariate survival analysis. In the whole cohort of patients, Kaplan-Meier curves showed that tumor FOXP3+(expression in nucleus and/or cytoplasm) conferred a significantly improved DFS ( $89.29 \%$ vs.71.79\%, log-rank $\mathrm{P}=0.013$, Figure $3 \mathrm{~A}$ ), but not a significantly improved OS (91.67\% vs.82.05\%, log-rank $\mathrm{P}=0.167$, Figure $2 \mathrm{~A}$ ). While, nuclear FOXP3 + was significantly associated with improved OS ( $94.92 \%$ vs. $82.81 \%$, Log-rank $\mathrm{P}=0.022$, Figure $2 \mathrm{~B}$ ) and DFS (91.53\% vs.76.56\%, Log-rank $\mathrm{P}=0.026$, Figure $3 \mathrm{~B}$ ) significantly. However, cytoplasmic FOXP3+ had not significant correlation with OS and DFS $(\log -\operatorname{rank} \mathrm{P}=0.355, \mathrm{P}=0.061$, Figure 2C, 3C). Univariate Cox analysis of clinicopathological characteristics indicated that nuclear FOXP3+was significantly associated with better OS (HR: 0.254; 95\%CI: 0.072-0.899; $\mathrm{P}=0.034$; Table 4) and DFS (HR: 0.334; 95\%CI: 0.121-0.919; $\mathrm{P}=0.034$; Table 5), and tumor FOXP3+ was only significantly associated with DFS (HR: 0.346; 95\%CI: 0.143-0.835; P=0.018, Table 5). 

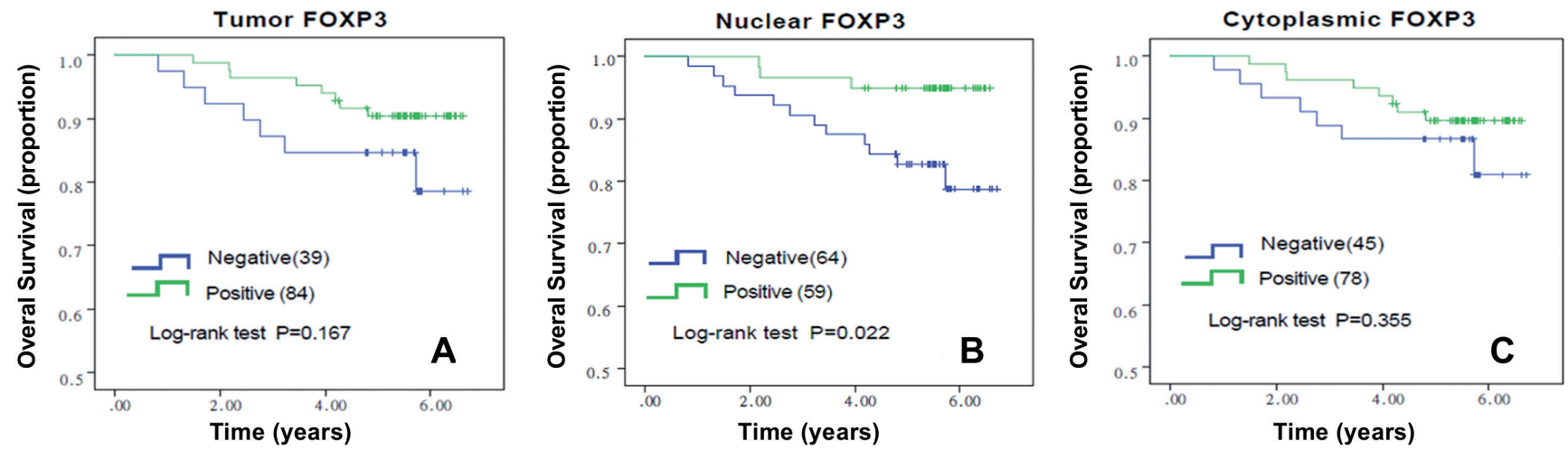

Figure 2. Forkhead box protein 3 (FOXP3) prognostic significance. Kaplan-Meier curves for OS associated with FOXP3 expression in breast cancer. Kaplan-Meier curves in two groups divided into (A) Tumor FOXP3-positive (cytoplasmic and/or nuclear expression) and FOXP3-negative, (B) Tumor nuclear FOXP3-positive and FOXP3-negative and (C) Tumor cytoplasmic FOXP3-positive and FOXP3-negative expression in tumor cells. P values were calculated with use of the log-rank test.
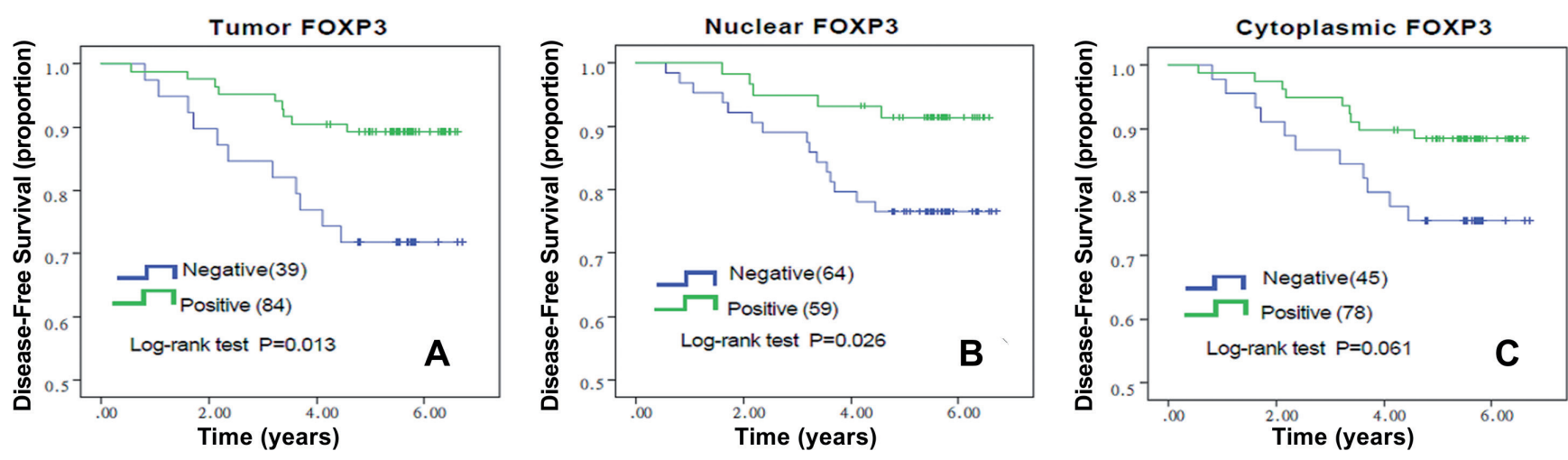

Figure 3. Forkhead box protein 3 (FOXP3) prognostic significance. Kaplan-Meier curves for DFS associated with FOXP3 expression in breast cancer. Kaplan-Meier curves in two groups divided into (A) Tumor FOXP3-positive (cytoplasmic and/or nuclear expression) and FOXP3-negative, (B) Tumor nuclear FOXP3-positive and FOXP3-negative and (C) Tumor cytoplasmic FOXP3-positive and FOXP3-negative expression in tumor cells. P values were calculated with use of the log-rank test.

Multivariate Cox regression analysis. All the predictors with $P$ values $<0.05$ in univariate Cox analyses were included in multivariate Cox analysis, which indicated that nuclear FOXP3+ was an independent prognostic factor for OS (HR: $0.245 ; 95 \%$ CI: $0.067-0.892 ; \mathrm{P}=0.033$, Table 4). By contrast, neither the tumor
FOXP3+, nor cytoplasmic FOXP3+ was an independent prognostic factor for OS or DFS (P>0.05, Table 4, 5). In addition, the multivariate analysis showed that vessel tumor embolus appeared to be an independent risk factor, and positive-ER was an independent protective factor for both OS and DFS (Table 4, 5).

Table 4. Univariate and multivariate analyses (Cox regression) for OS

\begin{tabular}{|c|c|c|c|c|c|c|}
\hline \multirow{2}{*}{ Variable } & \multicolumn{3}{|c|}{ Univariate analysis for OS } & \multicolumn{3}{|c|}{ Multivariate analysis for OS } \\
\hline & $\mathrm{HR}$ & $95 \%$ CI & P-value & HR & $95 \%$ CI & P-value \\
\hline Vessel tumor embolus & 3.988 & $1.419-11.209$ & 0.009 & 3.206 & $1.100-9.341$ & 0.033 \\
\hline ER-positive & 0.204 & $0.058-0.726$ & 0.014 & 0.167 & $0.045-0.621$ & 0.008 \\
\hline Tumor FOXP3+ & 0.496 & $0.180-1.368$ & 0.176 & 0.431 & $0.147-1.260$ & 0.124 \\
\hline Cytoplasmic FOXP3+ & 0.622 & $0.226-1.716$ & 0.359 & 0.46 & $0.156-1.357$ & 0.159 \\
\hline Nuclear FOXP3+ & 0.254 & $0.072-0.899$ & 0.034 & 0.245 & $0.067-0.892$ & 0.033 \\
\hline
\end{tabular}


Table 5. Univariate and multivariate analyses (Cox regression) for DFS

\begin{tabular}{|c|c|c|c|c|c|c|}
\hline \multirow{2}{*}{ Variable } & \multicolumn{3}{|c|}{ Univariate analysis for DFS } & \multicolumn{3}{|c|}{ Multivariate analysis for DFS } \\
\hline & $\mathrm{HR}$ & $95 \% \mathrm{CI}$ & P-value & $\mathrm{HR}$ & $95 \% \mathrm{CI}$ & P-value \\
\hline Positive nodes & 2.795 & $1.074-7.276$ & 0.035 & 1.901 & $0.612-5.905$ & 0.266 \\
\hline Vessel tumor embolus & 5.21 & $2.077-13.069$ & $<0.001$ & 3.69 & $1.393-9.778$ & 0.009 \\
\hline ER-positive & 0.332 & $0.128-0.865$ & 0.024 & 0.335 & $0.122-0.921$ & 0.034 \\
\hline High Ki67 & 4.597 & $1.066-19.818$ & 0.041 & 2.468 & $0.559-10.895$ & 0.233 \\
\hline TNM stage III & 4.648 & $0.965-22.386$ & 0.055 & 1.926 & $0.280-13.235$ & 0.505 \\
\hline Tumor FOXP3+ & 0.346 & $0.143-0.835$ & 0.018 & 0.392 & $0.150-1.020$ & 0.055 \\
\hline Cytoplasmic FOXP3+ & 0.441 & $0.183-1.065$ & 0.069 & 0.427 & $0.161-1.135$ & 0.088 \\
\hline Nuclear FOXP3+ & 0.334 & $0.121-0.919$ & 0.034 & 0.465 & $0.150-1.441$ & 0.185 \\
\hline
\end{tabular}

\section{Discussion}

The extent of FOXP3 expression in human breast cancer cells is still in a matter of debate. Ladoire $S$ et al. [7] reported that approximately $57 \%$ of HER $2+$ breast tumors were scored positive for FOXP3 in cytoplasm. Lopes LF et al. [14] observed a higher FOXP3 cytoplasmic expression rate (83\%) in tumor cells of TNBC tissue samples. In our study, we found that $63.41 \%$ of breast tissues expressed cytoplasmic FOXP3, with the highest expression ratio in TNBC $(88.00 \%)$, which is similar to the study of Lopes LF et al. [14]. This indicated that FOXP3 expression ratios range among different molecular subtypes of breast cancer. In addition, we detected tumor nuclear FOXP3 expression in 59 out of 123 specimens (47.97\%), with the highest ratio in the Luminal A subtype (68.18\%). It suggested that different analyzed subcellular localizations of FOXP3 expression may be another consequence for the various results above. Further reasons for the discrepancy in FOXP3 expression may be due to the various interpretations, the primary antibody concentrations, the times of antigen retrieval and the laboratory standards in various studies. It reported that some studies could not detect any significant levels of FOXP 3 expression in human breast cancer specimens $[15,16]$.

The clinical and prognostic implication of FOXP3 expression in breast cancer cells is still controversial. Increasing vitro studies point to the critical role of FOXP3 as a tumor suppressor gene in breast cancer models, transcriptionally repressing expression of these mediators (HER2/ErbB2, SKP2, SATB1 et al. $[3,5,6])$ that are involved in mammary tumorigenesis and epithelial-mesenchymal transitions (EMT) [17, 18]. Zhang $\mathrm{C}$ et al. [19] identified the adhesion molecule CD44 as a direct target of FOXP3. They demonstrated that FOXP3 significantly inhibits adhesion, invasion and metastasis of breast cancer cells in vivo by binding to the promoter of CD44 to suppress its protein expression. Accordingly, we found that tumor/nuclear FOXP3 + cases were significantly associated with negative vessel tumor embolus, which was an independent risk factor for breast cancer prognosis. It caused by the dysfunctional cell-cell adhesive junctions and related to the complex EMT and metastasis process $[20,21]$.
However, conflicting clinical results can't draw the same conclusion as that from vitro studies. Ladoire $S$ et al. [8] suggested that cytoplasmic and/or nuclear FOXP3+ in breast cancer was associated with better OS $(\mathrm{P}=0.003)$ in 1,097 patients with HER2+ breast cancer treated with neo-adjuvant chemotherapy. In our study, it demonstrated that nuclear FOXP3+ improved OS in patients without any neoadjuvant therapy. In sharp contrast to a putative onco-suppressor role for FOXP3, some studies of human cancer samples point to its pro-metastatic action in vivo, based on the correlation between FOXP3 expression and poor prognosis. Merlo et al. [4] reported that FOXP3 expression in tumors was associated with worse OS, regardless of the cellular localization. Kim et al. [9] found that FOXP3 expression in nucleus and/or cytoplasm was related to high Ki-67 index and poor DFS and disease-specific survival (DSS) in the node-positive subgroup. It is in contrast to our findings that nuclear FOXP3+ patients were associated with low Ki67 index $(\mathrm{P}=0.041)$ and better OS $(\mathrm{P}=0.033)$ significantly. One reason for this discrepancy may be that Kim et al. [9] did not analyze the nuclear FOXP3+ and cytoplasm FOXP3+ separately. It may also be due to the different cut-off points of Ki67 index. In our study, the cutoff point of Ki67 index was 30\%, instead of $14 \%$ in Kim et al. [9]. The proliferation marker Ki67 has been investigated as an important prognostic and predictive marker for breast cancer. However, the best cut-off point and the best methods for determination are still under debate $[11,22,23]$.

Precise reasons for the contradiction above remain unclear, but it might be explained in several ways. FOXP3 up- or down- regulates a large number of genes and acts as both a transcriptional activator and repressor [24]. It cannot be excluded that FOXP3 has a janus role regulating both proliferation and metastatic spread of tumor cells, displaying either anti-tumor or tumorgenic activities. In addition, the differences in the populations, races, disease stages, and treatment conditions, may also lead to the discrepancy [25]. Furthermore, the different subcellular localization of FOXP3 expression may influence its prognostic significance in breast cancer. In our study, we analyzed the values of tumor nuclear FOXP3+ and cytoplasm FOXP3+ separately. We found that 
the nuclear FOXP3+ ratio was higher in patients with low Ki67 index, indicating that nuclear FOXP3+ tumors are low proliferative abilities. This is in line with our survival analysis that nuclear FOXP3+ was an independent prognostic factor for better OS $(\mathrm{P}=0.033)$, which was similar to the study of Takenak et al. [26]. But cytoplasmic FOXP3+ was of no prognostic significance in our study. Therefore, we thought that cytoplasmic FOXP3 lost the anti-proliferative ability of a transcription factor in nucleus. Accordingly, researches have reported several possible factors causing the deregulation of FOXP3 localization and failure to translocate to the nucleus in breast cancer cells. It's suggested that frequent FOXP3 gene mutations and deletions, which may include nuclear localization signals surrounding the FKH domain of FOXP3, post-translational modifications, splice variations and the methylation of FOXP3 promoter may result in cytoplasmic localization of FOXP3 protein in breast cancer cells [27, 28]. Clearly, further studies using multiple in vitro and in vivo models are needed to examine the putative FOXP3 roles in breast cancer.

In summary, our study found that the prognostic significance of FOXP3 expression in breast invasive ductal carcinoma specimens is relevant to the different subcellular localizations of FOXP3. Nuclear FOXP3 demonstrated an independent prognostic factor for improved OS, whereas cytoplasmic FOXP3 was of no prognostic significance. This result may be caused by scant data and short follow-up time of our study. Therefore, more study data is needed to clarify the different values and molecular mechanisms of FOXP3 in heterogeneous subcelluar location. Further study is necessary to assess alterations in the DNA, mRNA and protein levels of FOXP3, which may provide an insight into the biological and clinical implications of FOXP3 expression in breast cancer. The discovery of genes and/or cellular functions regulated by FOXP3 in tumor cells will provide the rational explanation of its role and the proof of its anti-proliferative function, which would provide a novel therapeutic target in vivo. The data identify FOXP3, as a novel, independent prognostic factor, might aid in identifying subgroups of patients who are more likely to have a poor outcome and to whom specific therapies might be directed.

\section{References}

[1] TRIULZI T, TAGLIABUE E, BALSARI A, CASALINI P. FOXP3 expression in tumor cells and implications for cancer progression. J Cell Physiol 2013; 228: 30-35. https://doi. org/10.1002/jcp. 24125

[2] MARTIN F, LADOIRE S, MIGNOT G, APETOH L, GHIRINGHELLI F. Human FOXP3 and cancer. Oncogene 2010; 29: 4121-4129. https://doi.org/10.1038/onc.2010.174

[3] ZUO T, WANG L, MORRISON C, CHANG X, ZHANG H et al. FOXP3 is an X-linked breast cancer suppressor gene and an important repressor of the HER-2/ErbB2 oncogene. Cell 2007; 129: 1275-1286. https://doi.org/10.1016/j.cell.2007.04.034
[4] MERLO A, CASALINI P, CARCANGIU ML, MALVENTANO C, TRIULZI T et al. FOXP3 expression and overall survival in breast cancer. J Clin Oncol 2009; 27: 1746-1752. https://doi.org/10.1200/JCO.2008.17.9036

[5] ETIKALA DM, LIU R, WANG L. FOXP3-microRNA146-NF-kappaB as oncotarget. Oncoscience 2015; 2: 839-840.

[6] MCLNNES N, SADLON TJ, BROWN CY, PEDERSON S, BEYER $\mathrm{M}$ et al. FOXP3 and FOXP3-regulated microRNAs suppress SATB1 in breast cancer cells. Oncogene 2012; 31: 1045-1054. https://doi.org/10.1038/onc.2011.293

[7] LADOIRE S, ARNOULD L, MIGNOT G, COUDERT B, REBE $\mathrm{C}$ et al. Presence of Foxp3 expression in tumor cells predicts better survival in HER2-overexpressing breast cancer patients treated with neoadjuvant chemotherapy. Breast Cancer Res Treat 2011; 125: 65-72. https://doi.org/10.1007/s10549-010-0831-1

[8] LADOIRE S, MIGNOT G, DALBAN C, CHEVRIAUX A, ARNOULD L et al. FOXP3 expression in cancer cells and anthracyclines efficacy in patients with primary breast cancer treated with adjuvant chemotherapy in the phase III UNICANCER-PACS 01 trial. Ann Oncol 2012; 23: 2552-2561. https:// doi.org/10.1093/annonc/mds028

[9] KIM MH, KOO JS, LEE S. FOXP3 expression is related to high Ki-67 index and poor prognosis in lymph node-positive breast cancer patients. Oncology 2013; 85: 128-136. https:// doi.org/10.1159/000351473

[10] ELSTON CW, ELLIS IO. Pathological prognostic factors in breast cancer. I. The value of histological grade in breast cancer: experience from a large study with long-term follow-up. Histopathology 1991; 19: 403-410. https://doi. org/10.1111/j.1365-2559.1991.tb00229.x

[11] DENKERT C, BUDCZIES J, VON MINCKWITZ G, WIENERT S, LOIBL $S$ et al. Strategies for developing Ki67 as a useful biomarker in breast cancer. Breast 2015; 24: S67-S72. https://doi.org/10.1016/j.breast.2015.07.017

[12] HAMMOND ME, HAYES DF, DOWSETT M, ALLRED DC, HAGERTY KL et al. American Society of Clinical Oncology/ College of American Pathologists guideline recommendations for immunohistochemical testing of estrogen and progesterone receptors in breast cancer (unabridged version). Arch Pathol Lab Med 2010; 134: e48-e72.

[13] WOLFF AC, HAMMOND ME, HICKS DG, DOWSETT M, MCSHANE LM et al. Recommendations for human epidermal growth factor receptor 2 testing in breast cancer: American Society of Clinical Oncology/College of American Pathologists clinical practice guideline update. Arch Pathol Lab Med 2013; 138: 241-256. https://doi.org/10.5858/ arpa.2013-0953-SA

[14] LOPES LF, GUEMBAROVSKI RL, GUEMBAROVSKI AL, KISHIMA MO, CAMPOS CZ et al. FOXP3 transcription factor: a candidate marker for susceptibility and prognosis in triple negative breast cancer. Biomed Res Int 2014; 2014: 341654.

[15] DROESER RA, OBERMANN EC, WOLF AM, WALLNER $S$, WOLF D et al. Negligible nuclear FOXP3 expression in breast cancer epithelial cells compared with FOXP3-positive T cells. Clin Breast Cancer 2013; 13: 264-270. https://doi. org/10.1016/j.clbc.2013.02.009 
[16] WOLF D, WOLF AM, TZANKOV A. Comment on „Cutting edge: depletion of Foxp3+ cells leads to induction of autoimmunity by specific ablation of regulatory T cells in genetically targeted mice“. J Immunol 2010; 184: 4051-4051. https://doi. org/10.4049/jimmunol.1090014

[17] RECOUVREUX MS, GRASSO EN, ECHEVERRIA PC, VIEGAS LR, CASTILLA LH et al. RUNX1 and FOXP3 interplay regulates expression of breast cancer related genes. Oncotarget 2016; 7: 6552-6565.

[18] LIU R, LIU C, CHEN D, YANG WH, LIU X et al. Foxp3 controls an miR-146/NF- $\kappa \mathrm{B}$ negative feedback loop that inhibits apoptosis in breast cancer cells. Cancer Res 2015; 75: 1703-1713. https://doi.org/10.1158/0008-5472.CAN-14$\underline{2108}$

[19] ZHANG C, XU Y, HAO Q, WANG S, LI H et al. FOXP3 suppresses breast cancer metastasis through downregulation of CD44. Int J Cancer 2015; 137: 1279-1290. https://doi. org/10.1002/ijc.29482

[20] FORONI C, BROGGINI M, GENERALI D, DAMIA G. Epithelial-mesenchymal transition and breast cancer: Role, molecular mechanisms and clinical impact. Cancer Treat Rev 2012; 38: 689-697. https://doi.org/10.1016/j. ctrv.2011.11.001

[21] WARTENBERG M, ZLOBEC I, PERREN A, KOELZER VH, GLOOR B et al. Accumulation of FOXP3+ T-cells in the tumor microenvironment is associated with an epithelialmesenchymal-transition-type tumor budding phenotype and is an independent prognostic factor in surgically resected pancreatic ductal adenocarcinoma. Oncotarget 2015; 6: 4190-201. https://doi.org/10.18632/oncotarget.2775
[22] YERUSHALMI R, WOODS R, RAVDIN PM, HAYES MM, GELMON KA. Ki67 in breast cancer: prognostic and predictive potential. Lancet Oncol 2010; 11: 174-183. https://doi. org/10.1016/S1470-2045(09)70262-1

[23] REGAN MM, PAGANI O, FRANCIS PA, FLEMING GF, WALLEY BA et al. Predictive value and clinical utility of centrally assessed ER, PgR, and Ki-67 to select adjuvant endocrine therapy for premenopausal women with hormone receptor-positive, HER2-negative early breast cancer: TEXT and SOFT trials. Breast Cancer Res Treat 2015; 154: 275-286. https://doi.org/10.1007/s10549-015-3612-Z

[24] KATOH H, ZHENG P, LIU Y. Signalling through FOXP3 as an X-linked tumor suppressor. Int J Biochem Cell Biol 2010; 42:1784-1787. https://doi.org/10.1016/j.biocel.2010.07.015

[25] LIN SC, GAN ZH, YAO Y, MIN DL. The prognostic value of forkhead box P3 expression in operable breast cancer: a largescale meta-analysis. PLoS One 2015; 10: e0136374. https://doi. org/10.1371/journal.pone.0136374

[26] TAKENAKA M, SEKI N, TOH U, HATTORI S, KAWAHARA A et al. FOXP3 expression in tumor cells and tumor-infiltrating lymphocytes is associated with breast cancer prognosis. Mol Clin Oncol 2013; 1: 625-632. https://doi.org/10.3892/ $\underline{\text { mco.2013.107 }}$

[27] YUE X, TRIFARI S, ÄIJO T, TSAGARATOU WA, PASTOR WA et al. Control of Foxp3 stability through modulation of TET activity. J Exp Med 2016; 213: 377-397. https://doi. org/10.1084/jem.20151438

[28] BUCHYNSKA LG, IURCHENKO NP, VERKO NP, NEKRASOV KA, KASHUBA VI. FOXP3 gene promoter methylation in endometrial cancer cells. Exp Oncol 2015; 37: 246-249. 